\title{
La enseñanza de español en el Club de mujeres Ebell de Los Ángeles: la labor de Aurelia Bórquez (1914-1917)*
}

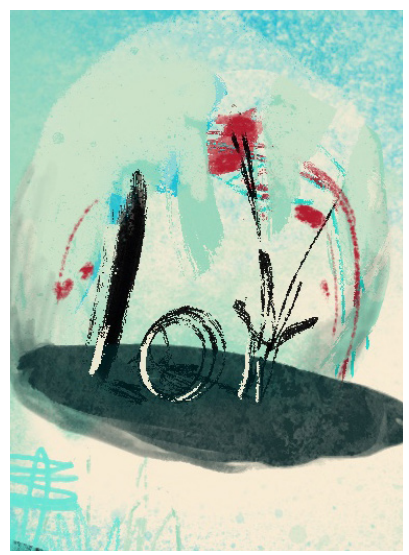

María Ángeles García Aranda

Universidad Complutense de Madrid, España

magaranda@filol.ucm.es

Trabajo recibido el 8 de julio de 2020 y aprobado el 9 de marzo de 2021.

\section{Resumen}

Este artículo se ocupa del método didáctico creado por la mexicana Aurelia Bórquez para enseñar a sus alumnas del Club de mujeres Ebell español. Tras repasar sus circunstancias vitales, se presenta el sistema, natural y directo, basado en oraciones, cuentos y leyendas que ideó y que puso en práctica en los primeros años de la pasada centuria, lo que supone una contribución a la historia de la enseñanza del español como lengua extranjera en una época, en un país, en una institución y por una autora todavía poco conocidos.

Palabras clave: Español como lengua extranjera, Estados Unidos, Aurelia Bórquez, siglo XX

Teaching Spanish at the Ebell Women's Club in Los Angeles: the work of Aurelia Bórquez (1914-1917)

\begin{abstract}
This paper deals with the didactic method created by the Mexican Aurelia Bórquez to teach her students from the Spanish Ebell Women's Club. After reviewing his life circumstances, is presented, the natural and direct system, based on prayers, stories and legends that he devised and put into practice in the first years of the last century, which represents a contribution to the history of the teaching of the Spanish as a foreign language in a time, in a country, in an institution and by an author still little known.
\end{abstract}

Keywords: Spanish as a foreign language, United States, Aurelia Bórquez, 2oth century

* Este trabajo se enmarca dentro del Proyecto de Investigación 'Biblioteca Virtual de la Filología Española. Fase IV: implementaciones y mejoras. Metabúsquedas. Gestores bibliográficos' (PID2020-112795GB-loo). 


\section{Ensino de espanhol no Ebell Women's Club em Los Angeles: o trabalho de Aurelia Bórquez (1914-1917)}

\section{Resumo}

Este artigo trata do método didático criado pela mexicana Aurelia Bórquez para ensinar suas alunas do Clube Feminino Ebell espanhol. Depois de rever as circunstâncias de sua vida, o sistema é apresentado, natural e direto, a partir de orações, histórias e lendas que ele idealizou e colocou em prática nos primeiros anos do século passado, o que representa uma contribuição para a história do ensino da O espanhol como língua estrangeira numa época, num país, numa instituição e por um autor ainda pouco conhecido.

Palavras-chave: Espanhol como língua estrangeira, Estados Unidos, Aurelia Bórquez, século 20

\section{Introducción}

A finales del siglo XIX, con el apogeo de los movimientos feministas en Estados Unidos -especialmente la Convención de Seneca Falls en Nueva York (1848) y la creación de la National Woman Suffrage Association (1868) - , se funda el Club de Mujeres Ebell en la ciudad de Los Ángeles (1894), urbe que, gracias al oro, la llegada del ferrocarril y el descubrimiento del petróleo, conocía un momento de desarrollo y esplendor.

El Club Ebell, llamado así en honor del defensor de la educación de la mujer ${ }^{1}$ que lo inspiró, Adrian Ebell, se unió en 1897 a la General Federation of Women's Clubs ${ }^{2}$ para "avanzar en todas las líneas de la cultura general; para llevar a cabo una labor educativa y filantrópica; y hacer cualquier cosa en la realización de los propósitos anteriores que una persona física pudiera hacer" (1923, 6, cita traducida por la autora).

Unos años después de su fundación, en 1921, reconocen las responsables de la institución que "miles de mujeres han aprovechado las oportunidades educativas y culturales que ofrece sus departamentos" (cita traducida por la autora). Entre esos departamentos, y dada la presencia hispana en el sur de Estados Unidos a comienzos del siglo $\mathrm{XX},{ }^{3}$ se encontraba el de Español que, además de organizar eventos musicales y reuniones gastronómicas,

1 Las primeras reuniones de la Sociedad Ebell se produjeron en Oakland en 1876.

2 Josiah Evans Cowles, presidenta de la General Federation of Women's Club en 1916, escribe unos años después que "sólo cuatro años antes de esta época, en abril de 1890 , se organizó en la ciudad de Nueva York la Federación General de Clubes de Mujeres cuya influencia se extendió rápidamente. Esta organización apolítica y no comercial atrajo hacia sí a grupos de mujeres serias y con visión de futuro en todos los sectores del país. Por lo que, independientemente de las condiciones locales, The Ebell of Los Angeles nació en un momento propicio, cuando el mundo estaba maduro para el gran movimiento de clubes (1923, 6, cita traducida por la autora).

3 La población española y mexicana ha estado presente en Los Ángeles a lo largo de su historia. Los Ángeles fue fundada en 1781 por Felipe de Neve y perteneció a España hasta 1821, año de la independencia mexicana en el que comienza a depender de México. En 1848 se firma el Tratado de Guadalupe Hidalgo por el que se pone fin al conflicto entre México y Estados Unidos, y California, con su capital incluida, pasa a formar parte de Estados Unidos. 
impartía clases elementales, intermedias y avanzadas con notable éxito, ${ }^{4}$ tal y como se desprende de las palabras que figuran en el boletín de noviembre de 1923: "gran entusiasmo marcó la jornada inaugural del Departamento de Español tuvo un gran éxito, con un gran número de alumnos matriculados. Cada jueves nuevos miembros se registran para este popular curso". (1923, 16, cita traducida por la autora).

En las aulas de este selecto Club enseñó Aurelia Bórquez, ${ }^{5}$ mujer de ascendencia hispanomexicana que fue definida como "una mujer de cultura y con carácter" con un gran "conocimiento de la vida" (1923, 127, cita traducida por la autora). Para sus alumnas elaboró una serie de materiales "adoptados en muchas escuelas" (1923, 127, cita traducida por la autora). ${ }^{6}$ Su método consistía en enseñar la gramática evitando la memorización de tediosas reglas y hacerlo, en cambio, a través de textos lúdicos que permitían al alumno aprender de forma natural y divertida. Para familiarizar a sus estudiantes con la gramática y el léxico del español en las primeras clases se servía de frases cortas u oraciones y de breves repertorios léxicos que recogían el vocabulario utilizado. Para las clases intermedias y superiores recopiló textos de diversa tipología adaptados a la realidad americana, de manera que enseñó español a través de fábulas, leyendas, cuentos y biografías mexicanos, esto es, procedentes de la tierra de sus padres y que resultaban más próximos geográficamente. En todos ellos fue introduciendo, con cuidado y dedicación, la realidad lingüística y sociocultural de México, de modo que sus textos resultan muy interesantes para estudiar la presencia de variación en las clases de ELE, pues con frecuencia reproducen escenas de la vida americana de la clase alta mexicana y las variedades lingüísticas funcionales a ellas asociadas.

Las páginas siguientes están dedicadas al método didáctico de Aurelia Bórquez: tras repasar sus circunstancias vitales, esenciales para entender el contenido de sus textos, se presenta el sistema natural y directo que ideó para enseñar español en el Club Ebell, lo que supone una contribución a la

\footnotetext{
4 El español, cuya enseñanza deja de ser financiada por el Gobierno de California, había quedado relegado al ámbito doméstico, por lo que las clases del Club Ebell serían de interés no solo para los hablantes de inglés, sino también para los hijos de inmigrantes mexicanos que quisieran aprender o mejorar su dominio del español. Lamar Prieto $(2018,15-16)$ así explica la situación que vivía el español en la centuria anterior: “al quedar relegado al ámbito de lo doméstico y de la interacción informal, los hablantes de español en California fueron, progresivamente, bien perdiendo registros pragmáticos, bien ampliando los campos de acción de determinados registros. O más que perdiéndolos, para el caso de los más jóvenes, no llegando a adquirirlos: si no puedo dirigirme a la Administración en español, probablemente nunca aprenda ni pueda transmitir los recursos para hacerlo; si no recibo formación reglada en español, es muy complicado que adquiera competencia pragmática para determinadas situaciones o que maneje el estándar escrito".

5 Ella lo califica como “el club educativo más importante de Los Angeles, California” (1917, 59, cita traducida por la autora).

6 Según consta en los boletines del Club Ebell (1923-1927), otros textos que se utilizaron en las clases de español en las primeras décadas de la centuria fueron Brief Spanish grammar de Michael Angelo de Vitis, Exercises in Spanish composition del profesor de la Universidad de Boston Samuel Montefiore Waxman, First Spanish Course de J. D. M. Hills y E. C. Ford, los Temas españoles de James Pyle Wickersham Crawford o algunas comedias de Frederic William Morrison, Miguel Ramos Carrión y Luis Cocat. También en estas primeras décadas impartieron clases de español en el Club Ebell Madeleine Novion y María López de Lowther.
} 
historia de la enseñanza del español como lengua extranjera en una época, en un país, en una institución y por una autora todavía poco conocidos. ${ }^{7}$

\section{Biobibliografía de Aurelia Bórquez de Whenthoff}

María Aurelia Bórquez nació en Tucson (Arizona) en 1872. Sus padres, los acaudalados Modesto Bórquez y María Juana Josefa Loreto Ferreira Bórquez, eran hijos de españoles afincados en Hermosillo (Sonora, México) que, ante las revueltas ocurridas a finales de la centuria, se vieron obligados a emigrar a Estados Unidos. ${ }^{8}$ Aurelia Bórquez, junto con sus cuatro hermanos, pasó sus primeros años de vida en Tucson y Globe y, tras cursar estudios de magisterio en la Arizona Territorial Normal School -luego Arizona State University—, marchó con su familia a Los Ángeles en 1905.

A finales de la centuria, y según cuentan los periódicos de la época ( $E l$ Fronterizo, Tucsonense), Aurelia Bórquez se ocupó de la cátedra de inglés en el colegio de niñas de Hermosillo, el pueblo natal de sus padres. Debió de casarse con W. F. Whenthoff, con quien se instaló en Nogales y tuvo un hijo en 1897. En 1902 regresó a Estados Unidos y se instaló en Presscott y, unos años más tarde, debió de trasladarse a Los Ángeles, ciudad en la que continuó su labor docente en su universidad y en el Club Ebell, instituciones en las que enseñó su lengua materna, ${ }^{9}$ y en donde publicó sus obras. En 1922, seguramente volvió a México, pues escribe una carta a sus colegas del Club Ebell para informarles de que acaba de fundar "la Asociación Internacional Femenina" con el objetivo de "promover un mejor entendimiento y amistad entre todas las mujeres", ${ }^{10}$ acontecimiento que recogió la prensa de Ciudad de México, que destacó que "propone atraer al llamado sexo débil de todas las nacionalidades para formar un núcleo que se esforzará por elevar el nivel intelectual, moral y económico de las mujeres" (citas traducidas por la autora). Murió en 1965 en Texas.

\footnotetext{
7 Aunque desde diferentes perspectivas, para diferentes cronologías y con distinta profundidad hay numerosos trabajos que abordan el español en California (Acevedo 2006, Bancroft 1886a y 1886b, Blanco 1971, Lamar Prieto 2018, Marcos Marín 2007, Moreno de Alba y Perissinotto 1998, Moyna 2010, Parodi 2009 y 2011, Perissinotto 1992 y 1998, entre otros), todavía faltan estudios que se ocupen sobre cómo y con qué materiales se enseñó nuestra lengua en esta compleja zona de Estados Unidos. Para la enseñanza del español durante el siglo xix en los Estados Unidos es imprescindible el trabajo de Mar Vilar (2000), centrado en centros educativos, profesores y planes de estudio de Filadelfia, Virginia, Harvard, Yale, Columbia, Nueva York, Maryland, Princeton, Georgetown, Bowdoin, Dartmouth, Florida, Carolina del Norte, Carolina del Sur y Florida, principalmente.

8 Pertenecen a la generación que, según Lamar Prieto $(2018,11)$, “nació española, vivió su juventud como mexicana y murió estadounidense, en línea con la historia del territorio”.

9 Como se ha dicho, Aurelia Bórquez tuvo mucha relación con México a lo largo de su vida y debió de tener muy presentes sus orígenes y un gran conocimiento de la realidad de la patria de sus padres: “y un deseo adicional de ayudar a interpretar mi tierra natal a mi tierra de adopción. Sólo la historia del pasado cruel puede explicar las condiciones de su desdichado presente; y en estos mitos y tradiciones, que se remontan a la historia, el lector puede encontrar la clave de los hábitos de pensamiento, la credulidad infantil y muchas de esas viejas costumbres en la vida diaria de la gente común que entretienen y desconciertan al viajero ordinario" (1915, 5, cita traducida de la autora).

10 Reconoce en su carta que había “ciento cincuenta inscritos como miembros activos en la primera reunión, y esperamos tener pronto mil miembros. Se puede ver fácilmente que el elemento femenino de la Ciudad de México está interesado en este movimiento; los miembros incluyen estadounidenses, europeas, centroamericanas y sudamericanas, así como mujeres mexicanas" (1923, 126, cita traducida de la autora).
} 
Aurelia Bórquez es autora de A series of Spanish conversations in the conjugational order. A series of commercial letters and short stories (Los Ángeles, 1914), de Leyendas históricas mexicanas costumbes [sic] y mitología (Los Ángeles, 1915) y de Elementary Spanish reader-Cuentos fáciles ilustrados (Los Ángeles, 1917). La primera obra, fundamentada en la propia experiencia de la autora, constituye un método basado en las oraciones, en donde "la idea es enseñar al alumno a pensar en español adaptando la palabra a la acción y utilizando un método basado en oraciones. Las oraciones están dispuestas de modo que desarrollen un tema en lugar de dar oraciones sueltas para memorizar" $(1914$, 4, cita traducida por la autora). El segundo volumen formado por "algunas de las más interesantes de las muchas leyendas pintorescas del México antiguo" lo compuso para "ser utilizado como lectura complementaria por estudiantes de español en escuelas públicas y clases privadas" (1917, 5, cita traducida por la autora). El tercer tratado, dedicado a sus alumnos del Ebell Club de California, por quienes fue escrito en parte, es un "lector práctico para principiantes sobre el estudio del español” (1917, 5, cita traducida por la autora).

En esas obras defiende, además, la necesidad de saber español, especialmente en los estados fronterizos de Estados Unidos con México dada su situación demográfica. En una de las lecciones de A series of Spanish conversations in the conjugational order afirma que "de las lenguas extranjeras preferimos el español, porque es un idioma muy bonito. También pensamos que es el que necesitamos más en esta parte del país" (Bórquez 1914, 24) y en uno de los cuentos o anécdotas afirma que "en Arizona es necesario saber español por que muchos de los habitantes no saben inglés" (Bórquez $1917,19)$ y, en la página siguiente y tras narrar los errores lingüísticos producidos en la conversación entre un hombre mexicano y un hombre inglés por la falta de conocimiento de la lengua del otro, ${ }^{11}$ concluye "la moraleja: todo el mundo necesita estudiar español" (Bórquez 1917, 20).

Aurelia Bórquez escribe en un momento crucial para la historia de Arizona: de la dominación española de los siglos XVII y XVIII, y de la dependencia mexicana en el siglo XIX pasa a convertirse, en 1912, en el 48o estado de los Estados Unidos. El sur de Estados Unidos, durante este tiempo, se había convertido en una compleja realidad lingüística, pues diacrónicamente es preciso considerar una base lingüística española, ${ }^{12}$ una importante

11 La anécdota recoge la situación vivida por un inglés que vive en Arizona cuando, tras realizar algunas gestiones, vuelve a su casa: "Cuando vuelve halla a un hombre mexicano muy fino y cortés. Cuando el inglés entra, el hombre le dice ‘buenas noches, señor. ¿Cómo está usted?’ pero el inglés no habla español y piensa que le dice (come to stay). 'Come to stay, have you? You get out of my house!' El mexicano no sabe inglés y le dice ‘no entiendo, señor'. ‘Don’t intend to?’ dice el inglés muy disgustado. 'We will see about that'. El pobre mexicano está muy triste y dice 'amigo, amigo'. 'Yes, me go, me go, you better go before I kick you out', dice el inglés” $(1915,20)$ [el problema de comprensión proviene de la igualación fónica, que no semántica, que realizan los dos hablantes: ¿cómo está? se iguala fónicamente a come to stay?-/k^m 'tu: 'stel, que, en realidad, significa ¿vienes para quedarte?; no entiendo se iguala a don't intend to-/dornt In'tend ‘tu:/, que significa ¿no pretendes hacerlo?; y amigo se iguala a me go-/mi: 'gov/ que significa me voy, de ahí que las palabras corteses del mexicano sean interpretadas como una amenaza para el inglés, que acaba empujándolo a que se marche].

12 Sobre la procedencia de los primeros hablantes y las condiciones de uso de su lengua, Francisco Moreno Fernández sostiene que "al considerar estos expedicionarios en su conjunto, se aprecia que había algo más de un tercio de hombres con una forma de hablar que podríamos caracterizar como 'castellana norteña' (sin seseo, con consonantismo sólido); junto a ellos, otro tercio sería usuario de la incipiente variedad del español mexicano y algo menos de un tercio tendría una fonética de corte andaluz occidental-canario" (2008, 182). 
expansión geográfica debida a la llegada de colonos españoles y americanos (sobre todo mexicanos) y, ya en el siglo XIX, la generalización definitiva del inglés, hechos que determinaron la realidad lingüística actual.

Las décadas en que Bórquez desarrolla su actividad docente coinciden con la época en que el inglés ha arrinconado al español en California por su generalización en la esfera pública. ${ }^{13}$ Según recoge Moreno Fernández,

en 1850, la mitad de la población de Nuevo México hablaba español; en 1905 se mantenía esa proporción; en 1915, el $75 \%$ de los maestros hablaba y enseñaba en español y el $60 \%$ de los educadores no hablaba ni entendía el inglés; en 1921, el $26 \%$ de los pobladores de Arizona eran ciudadanos de México; en 1970 la proporción de hispanohablantes se había reducido al 8,8\% (Moreno Fernández 2008, 188).

Teniendo en cuenta su origen mexicano, la situación sociolingüística de Arizona y Los Ángeles y su pertenencia al Club Ebell, Aurelia Bórquez diseña un método de enseñanza de español que explota didácticamente la oración, el cuento y el relato breve para enseñar la gramática y el léxico de su lengua materna.

\section{El método Bórquez}

Aurelia Bórquez diseñó un método que pretendía conjugar oralidad y escritura en el que las oraciones eran las protagonistas del aprendizaje. En su primera obra, A series of Spanish conversations in the conjugational order. A series of commercial letters and short stories (Los Ángeles, 1914), las sesenta y una lecciones que ocupan la primera parte se articulan en torno a una serie de oraciones, secuenciadas por su complejidad, en las que se invita al alumno a trabajar con los elementos gramaticales y léxicos que aparecían en ellas: conjugar el verbo que se encontraba en las sentencias, cambiar su modo y su tiempo o componer nuevas oraciones con las unidades léxicas. Para completar y apoyar el aprendizaje del español a partir de oraciones, Bórquez incluye quince fábulas clásicas, una nomenclatura o repertorio temático, una lista de abreviaturas, veintisiete textos de ámbito comercial, una selección de textos poéticos, un vocabulario alfabético y una detallada exposición de la conjugación verbal española.

Sus Leyendas históricas mexicanas costumbes [sic] y mitología (Los Ángeles, 1915) están redactadas para "ser utilizadas como lectura complementaria

13 Afirma Lamar Prieto $(2018,12)$ en este sentido que "la situación legal de los hablantes de español va a sufrir un giro importante conforme avanza el siglo [XIX], ya que su lengua va a ir perdiendo peso específico a medida que la presencia de población anglosajona aumente. Y no se trata solo de que aumente en porcentaje, sino de que los puestos de poder van a quedar consignados no solo a sus cabezas, sino a la lengua en la que se hablan a sí mismos y con la que se comunican con sus congéneres directos: el inglés. Una vez que la mayoría anglosajona se constituya en tal —-bien sea en números o en poderes-, comenzará a planear la duda sobre la forma de distribución de la tierra californiana. Porque entonces ya no es la tierra california, sino que ya es Californian, californiana [...]. Los californios quedan excluidos de los nuevos mecanismos de posesión, producción y transmisión. Ya no son dueños de sus tierras, no poseen poder político y su lengua va siendo progresivamente arrinconada. Para cuando se promulgue la segunda Constitución de California como Estado de la Unión, en 188o, el español ya ni siquiera será objeto de debate, sino que habrá quedado fuera de la esfera de lo público. Y con él, la posible preeminencia de los californios, o de parte de ellos, en la nueva sociedad”. 
por estudiantes de español en escuelas públicas y clases privadas" (Bórquez 1915, 5, cita traducida por la autora), pues, una vez aprendida la gramática española a través de oraciones y fragmentos sencillos, recomienda avanzar en el aprendizaje con la lectura de textos más complejos.

Finalmente, en Elementary Spanish reader-Cuentos fáciles ilustrados (Los Ángeles, 1917) Aurelia Bórquez recoge los frutos de su método: "las primeras 73 páginas del libro fueron escritas por miembros del Departamento de Español del Ebell Club de Los Ángeles, después de haber cursado solo treinta lecciones con mi libro de texto Spanish Conversations" (Bórquez 1917, 8, cita traducida por la autora). El volumen lo completan dieciocho cuentos más sobre México y sus principales figuras políticas e históricas, y un vocabulario alfabético de topónimos, antropónimos y léxico común.

Como venía siendo habitual en la enseñanza de lenguas desde la centuria anterior (Germain 1993 y 1995, Howatt 1984, Richards y Rodgers 1986 y 1998, Sánchez Pérez 1992, Titone 1968, Vilar 2000), ${ }^{14}$ Bórquez defiende un método natural que prescinde de la memorización y los contenidos teóricos gramaticales (tal y como se había hecho en los métodos tradicionales) y aboga, en cambio, por la practicidad, por la utilidad y por "enseñar al alumno a pensar en español adaptando la palabra a la acción y utilizando un método basado en oración" (1914, 4, cita traducida por la autora). Esto es, trata de aplicar los principios sobre la enseñanza de lenguas en boga en el momento que apostaban por la lengua oral, por la repetición como forma de memorización, por la enseñanza práctica, por dejar la gramática en un segundo plano y por abandonar el método memorístico de reglas y palabras descontextualizadas de los sistemas anteriores (Sánchez Pérez 1992, Vilar 2000).

Bórquez, en la línea de los métodos diseñados por algunos de sus predecesores (Gouin, Ollendorff, Jacotot, Robertson, cfr. Sánchez Pérez 1992), entiende que la mejor forma de aprender una lengua extranjera es imitando el método natural con el que adquirimos la lengua materna, por lo que utiliza la oración y el verbo como base de su enseñanza. La novedad de Bórquez radica, seguramente, en que no crea series en donde se describe de forma impersonal y con ejemplos triviales la vida de hombres, cuadrúpedos, pájaros, reptiles, plantas y elementos, sino que se sirve de oraciones para describir la vida en el sur de Estados Unidos de la clase alta mexicana, esto es, personaliza y contextualiza con personajes, lugares y argumentos reales su enseñanza.

Pese a que no detalla su método para enseñar español, intercala a lo largo de sus obras una serie de principios que nos permiten descubrir cómo entendía que debía aprenderse una lengua:

14 Germain $(1995,116)$ sostiene en este sentido que "a mediados del siglo XIX, las deficiencias y dificultades del método de traducción gramatical llevaron a muchos a imaginar nuevas formas de enseñar idiomas modernos. Esta es la estela de este vasto 'movimiento previo a la reforma'” (cita traducida por la autora). Entre los autores que llevan a cabo diversas iniciativas por cambiar el modo de enseñar las lenguas vivas, Germain cita a Gottlieb Heness, a James Hamilton, a Thomas Prendergast, a Jean Joseph Jacotot, a Lambert Sauveur, a Claude Marcel y a François Gouin. 
a) Defensa de la lengua oral y su práctica, de manera que recomienda a los profesores que "insistan en conversar en español durante toda la clase" (1914, 5, cita traducida por la autora) y, como muestra de las preguntas que se pueden realizar para estimular la práctica de la lengua oral, sugiere a los profesores cuestiones como "cuando quiere estudiar español, ¿qué hace?, cuando sale de la casa ¿a dónde va?, cuando toma el carro ¿qué hace?, cuando llega a su destinación ¿qué hace?” (1914, 9). En la lección decimoctava, dedicada a la escuela, reconoce que "en la clase hablamos en español solamente porque es el único modo de aprender una lengua" $(1914,24)$ y en la vigésima tercera, dedicada al paseo por el campo, propone como ejercicio "conversar con los alumnos sobre a picnic" (1914, 31, cita traducida por la autora). En su última obra, en las páginas dedicadas a la pronunciación, vuelve a recomendar "no sobrecargar a los alumnos con reglas de pronunciación, simplemente enséñeles. Es mucho más fácil para los niños imitar que recordar las reglas, y no hay nada tan bueno como entrenar el oído" (1917, 9, cita traducida por la autora).

b) Uso de la oración como base de la enseñanza, pues en ella aparecen las palabras contextualizadas. Como se ha dicho, el método de Aurelia Bórquez descansa en la oración, es, como ella dice, "un método basado en oraciones" (1914, 4, cita traducida por la autora), por eso, "las preguntas y las respuestas deben estar en forma de oración" (1914, 5, cita traducida por la autora).

c) Elaboración de temas graduados a partir de oraciones reales que tratan sobre un tema de la vida cotidiana, "las oraciones están dispuestas de modo que desarrollan un tema" (1914, 4, cita traducida por la autora), lo que le permite introducir diversos núcleos temáticos con sus unidades léxicas correspondientes (primero sobre las acciones habituales en casa o en la escuela y, al final, el viaje por mar y el viaje en tren) y desarrollar en ellos los contenidos gramaticales (primero oraciones simples en presente y, en último lugar, oraciones subordinadas con tiempos de subjuntivo)

d) Escucha y lectura constante de las oraciones que van apareciendo en los temas, de modo que, entre las instrucciones para los profesores, están "lee y explique cada lección a los alumnos. Haga que las lean" $(1914,5)$.

e) Realización de prácticas con los verbos y las unidades léxicas de las oraciones para aprender, de manera natural y directa, la gramática del español. Es, sin duda alguna, el aspecto del método sobre el que más insiste Aurelia Bórquez con recomendaciones como "pida a los alumnos que vayan al pizarrón y conjuguen cada verbo de la lección en el tiempo en que está escrita la lección", "pídales que escriban oraciones que no sean de la lección usando las palabras de la lección", "cuando haya un cambio de tiempo o persona en la lección, pida a los alumnos que lean algunas de las lecciones anteriores y las transpongan al tiempo verbal" o "después de que se hayan introducido las tres partes principales del verbo, pida a los alumnos que digan las de los verbos utilizados en la lección, y pídales que formen oraciones usándolos" (1914, 24, citas traducidas por la autora) y, un poco más adelante, plantea como práctica "haga que los alumnos conjuguen este verbo (estar de acuerdo)" (1914, 31, cita traducida por la autora). 
f) Rechazo de la enseñanza gramatical a partir de una serie de reglas que deben memorizarse, tal y como ocurría con el método tradicional, por lo que evita "dar oraciones sueltas para memorizar" (1914, 4, cita traducida por la autora).

g) Utilización de la lengua meta, en este caso el español, desde la primera clase, por lo que todas las lecciones y todos los textos están compuestos en español. Ello exige al docente un gran conocimiento de la lengua que enseña y convierte, por tanto, en inútiles estos materiales si falta ese dominio.

h) Aprendizaje, junto a los contenidos lingüísticos, de aspectos socioculturales (actividades habituales, comidas, bebidas, compras, pasatiempos y juegos, religión) y pragmáticos (cortesía, interlocutores, contexto).

Una vez que el alumno se ha familiarizado con la gramática y el léxico del español, está listo para componer sus propias oraciones y sus propios textos y para entender y usar escritos de mayor dificultad y de otras tipologías.

Ahora bien, sintetizar y compendiar el contenido gramatical de una lengua en unas pocas oraciones distribuidas en varias lecciones acarrea, aunque se realicen constantes prácticas, algunas limitaciones, pues el aprendiz no cuenta con ningún material de apoyo en el que consultar los elementos, la estructura o el vocabulario de la lengua que está adquiriendo. Por ello, Aurelia Bórquez se sirve, tanto en el primer como en el último texto, de notas al pie de página para introducir comentarios gramaticales y léxicos que ayuden a la interpretación correcta de las oraciones y de los cuentos (lo que tampoco resulta extraño en la historia de los materiales de enseñanza de segundas lenguas, Germain 1993, Howatt 1984, Richards y Rodgers 1986 y 1998, Sánchez Pérez 1992, Titone 1968).

Por otro lado, y dado que en las series de oraciones el verbo y el vocabulario constituyen la clave del avance del aprendizaje, Aurelia Bórquez incluye en sus obras nomenclaturas, vocabularios alfabéticos o detalladas exposiciones de la conjugación verbal del español muy similares a los que venían componiéndose, en muchos casos, desde finales de la Edad Media.

Parece, pues, que Bórquez estaba familiarizada tanto con los materiales tradicionales de enseñanza de lenguas como con las nuevas corrientes desarrolladas en la segunda mitad de la centuria anterior. Con estos postulados, diseña un método para enseñar la pronunciación, la gramática y el léxico del español.

\subsection{La pronunciación y la ortografía}

Tanto en A series of Spanish conversations como en Elementary Spanish reader-Cuentos fáciles ilustrados las primeras lecciones están dedicadas a la pronunciación. Con un punto de partida claro, "no sobrecargue a los alumnos con reglas de pronunciación, simplemente enséñeles" (1917, 9, cita traducida por la autora), y con una apuesta firme por la repetición y la imitación de los sonidos de la lengua que se estudia, "es mucho más fácil para los niños imitar que recordar las reglas, y no hay nada tan bueno como 
entrenar el oído" (1917, 9, cita traducida por la autora), Aurelia Bórquez presenta el alfabeto español y su pronunciación.

Utilizando la comparación con los sonidos ingleses como método de enseñanza, iguala en las pronunciaciones de las dos lenguas las siguientes letras: $a, b, c h, e, f, i, k, l, m, n, o, p, q, s, t, u, v, w$ y $x$. Ofrece para ellas las siguientes transcripciones o sonidos: [ah], [beh], [cheh], [eh], [effeh], [ee], [kah], [elleh], [emeh], [eneh], [oh], [peh], [koo], [esseh], [teh], [oo], [veh], [doblióo] y [ehkis]. Esto es, siguiendo la tradición (apud García Aranda, 2020), a) equipara los sonidos vocálicos a los mismos en inglés o a otras secuencias, b) utiliza la $h$ para indicar que la vocal cierra sílaba, ayudando así a sus alumnos ingleses con la pronunciación, c) asimila los sonidos bilabial oclusivo/interrupto sonoro, labiodental fricativo/constrictivo sonora, ${ }^{15}$ palatal-postalveolar/prepalatal africado sordo, labiodental fricativo/constrictivo sordo, velar oclusivo/interrupto sordo, ${ }^{16}$ alveolar lateral sonoro, bilabial nasal sonoro, alveolar nasal sonoro, bilabial oclusivo/interrupto sordo, alveolar fricativo/constrictivo sordo, dentoalveolar oclusivo/interrupto sordo, aproximante labiovelar sonora ${ }^{17}$ y el grupo consonántico formado por velar oclusiva/interrupta sorda + alveolar fricativa/constrictiva sorda:

\begin{tabular}{cccc}
\hline Letra & Sonido & Letra & Sonido \\
\hline$a$ & {$[\mathrm{a}]$} & $b$ & {$[\mathrm{~b}]$} \\
\hline$e$ & {$[\mathrm{e}]$} & $v$ & {$[\mathrm{v}]$} \\
\hline$i, y$ & {$[\mathrm{ee}]$} & $c h$ & {$[\mathrm{t}]$} \\
\hline$o$ & {$[\mathrm{o}]$} & $f$ & {$[\mathrm{f}]$} \\
\hline$u$ & {$[00]$} & $c a, c o, c u, k, q$ & {$[\mathrm{k}]$} \\
\hline & $l$ & {$[\mathrm{l}]$} \\
\hline & $m$ & {$[\mathrm{~m}]$} \\
\hline & $n$ & {$[\mathrm{n}]$} \\
\hline & $p$ & {$[\mathrm{p}]$} \\
\hline & $s$ & {$[\mathrm{~s}]$} \\
\hline & $t$ & {$[\mathrm{t}]$} \\
\hline & $w$ & {$[\mathrm{w}]$} \\
& & $x$ & {$[\mathrm{ks}]$} \\
\hline
\end{tabular}

Tabla 1. Sonidos igualados en las dos lenguas.

15 Pese a que los gramáticos y ortógrafos de los siglos precedentes señalan la igualación en la pronunciación de v y b, es común en los textos que presenten su diferenciación con fines gráficos (Alonso 1967, Martínez Alcalde 2010); es decir, parece que en la diferencia b y v una cuestión son las grafías (a veces "artificialmente arcaizantes", Alonso 1967, 60) y otra muy distinta las pronunciaciones.

16 El tratamiento de la k como letra del alfabeto ha sido desigual a lo largo de la historia: entre 1815 y 1869 la k se excluyó del alfabeto (los autores reconocen que solo se usa en palabras de origen extranjero que la Academia prefiere escribir con c/qu, cfr. RAE 2010, 64-65 y 113), por lo que en muchas gramáticas de esa época no aparece entre los componentes del alfabeto español.

17 La w entró en el alfabeto español oficialmente en la ortografía de 1969. La primera vez que aparece esta letra dentro del alfabeto español es en la edición del DRAE de 1869, en donde se recoge que "con este carácter, que, por no ser necesario, no se incluye entre las letras de nuestro alfabeto, se han escrito y se escriben en castellano algunos nombres propios y otras palabras, que pronunciamos como si la v doble fuera sencilla" (803). Varias décadas antes, en 1788, el Diccionario castellano con las voces de ciencias y artes y sus correspondientes en las tres lenguas francesa, latina e italiana de Esteban de Terreros (Madrid, Viuda de Ibarra) señalaba que "no son letras usadas en Castilla, sino tomadas del Norte; pero siendo preciso por no carecer de algunas voces que se escriben con ellas, las usamos aquí. El sonido de ellas en nuestro idioma es el de la primera de u vocal y el de la segunda v consonante que hiere a la vocal que se sigue" (831). 
Tras advertir que $c h, l l$ y $r r$ son "consideradas letras simples" (1914, 6 y $1917,9,{ }^{18}$ cita traducida por la autora) y que nunca debe prescindirse de la tilde nasal en $\tilde{n}$ (" $\tilde{n}$ no es un $n$, y se debe tener mucho cuidado de no omitir la tilde que se coloca encima", 1914, 6 y 1917, 9, cita traducida por la autora), Bórquez se ocupa de los sonidos que necesitan alguna precisión por no ser idénticos en ambas lenguas o por no existir en inglés:

\begin{tabular}{|c|c|c|}
\hline \multicolumn{2}{|c|}{ Equiparación } & \multirow{2}{*}{ Sonido-grafía español y en inglés } \\
\hline Español & Inglés & \\
\hline $\begin{array}{l}\text { Interdental fricativa/constrictiva } \\
\text { sorda }\end{array}$ & $\begin{array}{l}\text { Dental fricativa/constrictiva } \\
\text { sorda }\end{array}$ & $\begin{array}{l}\text { ce, ci, za, ze, zi, zo, zu, "se les da el sonido de th en thin" (1914, } \\
\text { 6, cita traducida por la autora); "se pronuncia como en inglés: } \\
\text { suave delante de e, i y dura delante del resto de vocales" (1914, } \\
\text { 7, cita traducida por la autora); "se pronuncia como th en thin" } \\
\text { (1917, 9, cita traducida por la autora) }\end{array}$ \\
\hline $\begin{array}{l}\text { Alveolar oclusiva/interrupta } \\
\text { sonora }\end{array}$ & $\begin{array}{l}\text { Dental fricativa/constrictiva } \\
\text { sonora }\end{array}$ & $\begin{array}{l}\text { "th como en the" (1914, 7, cita traducida por la autora); "th como } \\
\text { en the, pero más suave" (1917, 9, cita traducida por la autora) }\end{array}$ \\
\hline Cero fonético & & h, "silencio" (1914, 7 y 1917-9, cita traducida por la autora) \\
\hline Velar fricativa/constrictiva sorda & $\begin{array}{l}\text { Glotal fricativa/constrictiva } \\
\text { sorda }\end{array}$ & ja, je, ji, jo, ju, ge, gi: [heh], [hotah], [Mé-hee-co] \\
\hline Palatal lateral sonora & Lateral + vocal palatal & $\begin{array}{l}\text { II, "a la II se le da el sonido de II en William" (1914, 6, cita } \\
\text { traducida por la autora); "like II in William" (1917, 9, cita traducida } \\
\text { por la autora) }\end{array}$ \\
\hline $\begin{array}{l}\text { Rótica simple (percusiva) alveolar } \\
\text { sonora }\end{array}$ & Aproximante alveolar sonora & $\begin{array}{l}\text { "r es larga al principio de una palabra y breve en otros lugares" } \\
(1914,7 \text { y } 1917,9 \text {, cita traducida por la autora) }\end{array}$ \\
\hline Rótica múltiple alveolar sonora & & $\begin{array}{l}\text { "rr nunca se usa al principio o al final de una palabra y siempre } \\
\text { se pronuncia como vibrante" (1914, } 7 \text { y 1917, 9, cita traducida por } \\
\text { la autora) }\end{array}$ \\
\hline
\end{tabular}

Tabla 2. Sonidos parecidos en las dos lenguas.

A esta lista había que añadir el sonido palatal nasal sonoro, que, según aparece en el deletreo inicial, se iguala a una nasal + vocal palatal (enyeh) y el palatal aproximante sonoro que, cuando es consonante, es "como en inglés" (1914, 7 y 1917, 9, cita traducida por la autora). Bórquez, además, insiste en la diferente pronunciación de gu y gü: "gua se pronuncia como wa; gue como we en went; güe [goo-eh]" (1917, 9, cita traducida por la autora), esto es, como [w], por su carácter (labio)velar, y como velar oclusiva/interrupta sonora.

Más interesante que el tratamiento que reciben los sonidos del español (poco original si se compara con lo que venía haciéndose, apud García Aranda, 2020) es la información que aparece sobre la pronunciación del español de América. Aurelia Bórquez, con orígenes mexicanos, señala que ll en España se pronuncia "y en Hispanoamérica" (1917, 9, cita traducida por la autora) y que $z$ en España "como $s$ en Hispanoamérica" (1917, 9, cita traducida por la autora), y en el deletreo inicial recoge $c$-[seh], $z$-[sehtah], lo que justifica afirmando que "la mayoría de las personas que aprenden español lo usarán allí" (1914, 6, ${ }^{19}$ cita traducida por la autora). Enseña, pues, lo que será más útil y cercano para sus estudiantes, sin importarle

18 Aurelia Bórquez, como la mayoría de textos de ELE, coincide con el momento de fijación ortográfica por el que discurría la Real Academia Española: en la Ortografía de 1754 los dígrafos ch y Il son considerados como letras del alfabeto, y no como dígrafos. Lo mismo ha ocurrido históricamente con rr.

19 El seseo y el yeísmo son dos fenómenos ampliamente documentados en la bibliografía sobre el español de América. Cfr. entre otros muchos, Aleza Izquierdo y Enguita Utrilla 2010, Alvar 1996, Fontanella de Weinberg 1992, Lipski 1996, Moreno de Alba 1993, Quesada Pacheco 200o, Quilis y Quilis Sanz 2002. 
consideraciones prescriptivistas o normativas que indicaban que el seseo o el yeísmo se encontraban entre los errores o faltas más habituales. ${ }^{20}$

La descripción fónica y ortográfica se completa, utilizando de nuevo un método que parte de la comparación entre las dos lenguas, con varias observaciones sobre las sílabas, las secuencias vocálicas tautosilábicas ${ }^{21}$ y su escritura (taray, hoy, convoy, ley, bou, carey, bejuí, apreciáis, buey, amortiguáis), sobre la acentuación en español, sobre el uso de mayúsculas en español ${ }^{22}$ o sobre puntuación. ${ }^{23}$

De manera más sencilla y simplificada, Aurelia Bórquez también se vale de las notas a pie de página para incluir información fónica y gráfica; así, señala en una nota la tilde diacrítica que permite diferenciar si-if de si-yes, recuerda que " $e$ se usa en lugar de $y$ debido a la eufonía. Precede a las palabras que empiezan por $i$ - o hi-" (1914, 17, cita traducida por la autora) y enseña que la abreviatura etc. "se pronuncia et cetera" (1914, 23, cita traducida por la autora).

\subsection{La morfología}

Como se ha señalado, Aurelia Bórquez no dedica un capítulo o capítulos específicos a describir la estructura de las palabras y sus elementos constitutivos, sino que va introduciendo las formas morfológicas del español en las notas a pie de página que completan las oraciones que constituyen la base de su método. La única concesión que se permite en este sentido es en su Elementary Spanish reader-Cuentos fáciles ilustrados, en donde en unas líneas introductorias advierte que en español los sustantivos terminados en - $a$, -dad, -ion y - $z$ "son femeninos", que el plural se forma "añadiendo - $s$ o -es al singular", que se forman derivados que significan "pequeño" con -ito, -ita o que -dad es el equivalente de -ty, -mente el de -ly y -ción el de -tion (1917, 11, citas traducidas por la autora).

Las notas, por su parte, permiten a Bórquez indicar las formas en español y su traducción al inglés de las clases de palabras, así como introducir sucinta información sobre la formación del género (todos los sustantivos terminados en -o masculinos salvo mano) y del número (vez > veces) de las categorías variables.

En cuanto a la morfología derivativa, hay notas para indicar el comportamiento semántico de algunos sufijos derivativos. Aurelia Bórquez, utilizando

20 La Real Academia, en el DRAE-1914, define sesear como "pronunciar la c como s por vicio o por defecto orgánico" (936) y yeísmo como "defecto que consiste en pronunciar la elle como ye, diciendo, por ejemplo, gayina por gallina; poyo por pollo” (pág. 106o).

21 Aurelia Bórquez recomienda trabajar con los alumnos las sílabas formadas por núcleos simples y las sílabas con núcleos complejos (ña, ca, que, qui, ga, gue, gui, az, ez, ya, yi, chu, cho, lla, causa, aplaudo, aire, hay, fiel, diócesis, veis, evacuo, triunfó, viuda, cual, ingenua, hijuela... 1917, 10).

22 Señala Bórquez que "las letras mayúsculas se utilizan solo en los nombres propios; al comienzo de una oración, a veces con nombres que expresan rango o dignidad, y al comienzo de cada línea de poesía" (1914, 6, cita traducida por la autora).

23 Afirma que “los signos de puntuación son los mismos en inglés que en español” salvo la interrogación y la exclamación cuyos "signos se colocan antes y se invierten" (1914, 6, cita traducida por la autora). 
la segmentación para identificar y aislar morfemas que son recurrentes, señala que -ero/-era y -ería son sufijos especialmente productivos que forman sustantivos denominales que indican, respectivamente, oficios u ocupaciones o el lugar en que se desarrolla y lugares, tiendas o establecimientos comerciales; que -ón/-ona es un sufijo aumentativo o que des- es un prefijo que se adjunta al verbo (ilustra el ejemplo descolgar) para indicar una acción opuesta a la indicada por la base. ${ }^{24}$

\subsection{El verbo}

Seguramente la clase de palabra que mejor y más pormenorizadamente está tratada en la obra de Aurelia Bórquez es el verbo. Dado que es la categoría más importante en el método Bórquez, en cada una de las sesenta y una lecciones se señala en negrita el verbo de cada oración y, entre paréntesis, se incluye el infinitivo y su traducción al inglés:

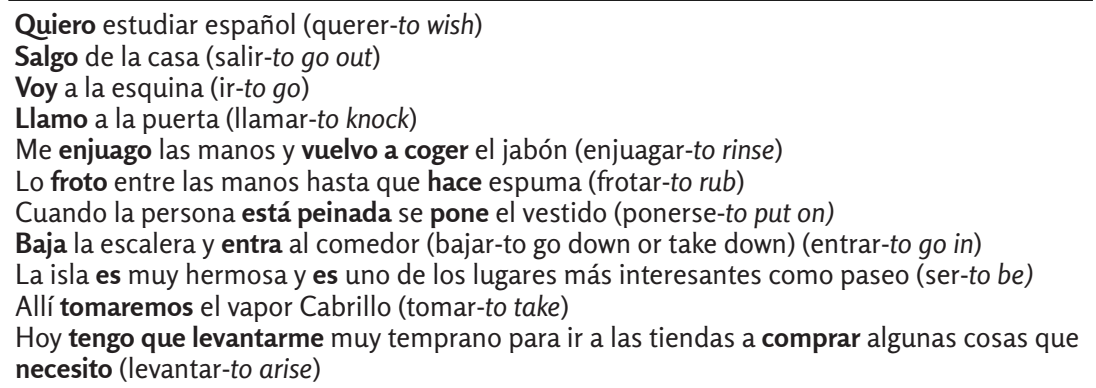

Tabla 3. Ejemplos del tratamiento del verbo.

Además, conocidas las dificultades de aprendizaje que genera el sistema verbal español, la mayoría de las notas a pie tratan sobre aspectos de esta categoría:

a) Numerosas notas constituyen paradigmas de conjugación de diferentes modos (primero en indicativo y después en subjuntivo), personas, números y tiempos de cada uno de los verbos aparecidos en las oraciones: querer, salir, ir, sentar, pedir, volver, leer, estar, oír, ser, tener, colgar, comenzar, despertar, verter, coger, decir, hacer, poner, ponerse, hacer, vestirse, dirigirse, preferir, atender, permanecer, vestirse, practicar, dormir, haber, gustar, ponerse, divertirse, ir, llegar, dar, platicar, salir, cocer, ver.

b) Otras notas sirven para introducir la forma (diferentes personas y tiempos del verbo auxiliar) y la traducción de varias perífrasis verbales: las aspectuales terminativas o perfectivas (han acabado de comer-they have finished eating, acabé de arreglar-I finished arranging, acaba de llegar-just arrived, acaban de llegar-have just arrived, acabado de leerfinished reading, acabamos de llegar-we had just arrived); las aspectuales incoativas (me puse a jugar-I began to play); las modales de obligación (tener que-to have to, tendré que comprar-I shall have to buy,

24 Las citas exactas son “-era, -ero al final de un sustantivo generalmente significan la persona o el lugar", pág. 13; -ría/-ería "al final de un sustantivo significa tienda”, pág. 66; “-on/-ona es un sufijo que indica aumentativo”, pág. 11 y “des- es un prefijo igual a un en inglés”, pág. 23 (citas traducidas por la autora). 
tuve que-I had to, tenía que-I had to, tuvieron que-they had to, tuvimos que-we had to); y las de estado resultante (está abotonado-is buttoned, está parado-has stopped).

c) En varias ocasiones las notas sirven para indicar aspectos semánticos de algunos verbos que presentan importantes diferencias en las dos lenguas. Así, por ejemplo, Bórquez trata de diferenciar, atendiendo a su aspecto léxico o modo de acción, estar y ser como verbo de estado episódico o transitorio (además de sus valores intransitivo y locativo, “cómo es una persona, dónde está una persona o qué está haciendo una persona", 1917, 11) y verbo de estado permanente ("para expresar lo que es una persona o cosa", 1917, 11, citas traducidas por la autora).

d) En otro comentario da cuenta de la diferencia en inglés, inexistente en español, entre los verbos to be able y can, ambos traducidos por poder, pero con diferentes restricciones temporales; a propósito de "la criada le dijo que no podía recibir, pero ella insistía en verme" indica que "no tenemos un verbo can en español" y traduce podría por would be able.

e) Otras notas, en cambio, aluden a la tipología verbal del español y tratan de caracterizar los verbos reflexivos o pronominales construidos con pronombres que, sin función sintáctica, denotan "que la acción es recibida por la persona que habla o la persona a la que se habla o de quien se habla, como lavar-to wash, lavarse-to wash oneself" (1917, 9, cita traducida por la autora) o de advertir sobre los usos impersonales de gustar-to like o de haber.

f) Bórquez también comenta la diferencia categorial de puesto como participio y como adjetivo y, por tanto, su diferente concordancia: invariable en el primer caso y concordando en género y número en el segundo. ${ }^{25}$

Ahora bien, las anotaciones más frecuentes que realiza Bórquez son las que vienen exigidas por las diferencias formales, los significados, los valores temporales y modales, los regímenes, las construcciones, la conjugación o la función de algunos verbos en las dos lenguas:

\begin{tabular}{|c|c|}
\hline $\begin{array}{l}\text { Subjuntivo vs. Present tense with } \\
\text { infinitive, may + infinitive }\end{array}$ & $\begin{array}{l}\text { no es difíil que compremos-it is not improbable that we may buy, } \\
\text { que veamos-is to see or that we many see, nos levantemos-we may } \\
\text { rise, culpemos-we may blame, sepa-may know, digamos-we may } \\
\text { say, veamos-may see, que me enseñe-that he may show me or to } \\
\text { show me, me vea-he may see me, salgamos-we may depart, haré } \\
\text { que me traigan-l will have them bring, haya tomado-may have } \\
\text { taken }\end{array}$ \\
\hline $\begin{array}{l}\text { Verbo de percepción oír + oración } \\
\text { de infinitivo }\end{array}$ & oi sonar la campanilla-I heard the bell ring \\
\hline $\begin{array}{l}\text { Verbos/usos verbales } \\
\text { impersonales }\end{array}$ & $\begin{array}{l}\text { hace un momento-a moment ago, se vende-is sold, hizo mucho } \\
\text { viento-it was very windy }\end{array}$ \\
\hline Gustar vs. to like & $\begin{array}{l}\text { no me gustarán-I will not like, no me gustan-I do not like, le gusta- } \\
\text { he likes, les gusta-they like, hace una semana-a week ago }\end{array}$ \\
\hline Sentir vs. to be sorry & sentirá mucho-he will be very sorry, siento mucho-I am very sorry \\
\hline $\begin{array}{l}\text { Andar '[artefacto o máquina] } \\
\text { moverse para ejecutar sus } \\
\text { funciones' }\end{array}$ & mi reloj anda bien-runs wells, \\
\hline
\end{tabular}

Tabla 4. Ejemplos de notas sobre cuestiones verbales.

25 Dice al respecto que "puesto es el participio pasado de poner, pero aquí [cuando tengo las medias y las ligas puestas] se usa como adjetivo y concuerda con el sustantivo en número y género" (1917, 17, cita traducida por la autora). 
A estas notas habría que añadir las que tratan de aclarar diferentes usos del subjuntivo; así, Bórquez, a través de los ejemplos, trata de transmitir que cuando no es solo una conjunción temporal, sino que también puede encabezar una prótasis condicional para lo que se exige este modo verbal o que los verbos de orden o mandato exigen subjuntivo cuando el sujeto de la subordinada no es el mismo que el de la principal. ${ }^{26}$

Pero las notas en la parte inferior de cada página no son suficientes para exponer las dificultades que entraña el sistema verbal español, por lo que Bórquez dedica íntegramente algunas de sus lecciones a la exposición de las conjugaciones de los verbos regulares e irregulares del español. La lección undécima está dedicada a los finales de infinitivo, gerundio y participio de los verbos regulares y de algunos irregulares (ir, volver, oír, poner, vestir, venir, morir, hacer, abrir, reñir...); la lección vigésima recoge los finales del pretérito perfecto de los verbos regulares; la lección trigésima novena reúne las terminaciones del imperativo de los verbos regulares y la lección cuadragésima primera, más extensa que el resto, está concebida para explicar detalladamente el modo subjuntivo.

Tras afirmar que "el estudio del modo subjuntivo es sumamente interesante e importante" (1914, 50, cita traducida por la autora) y que su uso es comparativamente mayor en español que en inglés, Bórquez introduce una serie de ejemplos que se podrían sintetizar de la siguiente forma: 1) contextos de modo dependiente (oraciones subordinadas sustantivas en donde el sujeto de la oración principal es diferente del de la oración subordinada) determinados por las nociones semánticas de afección (quiero que vaya, siento que vaya, me alegro que la vea), necesidad (es preciso que vaya), mandato u orden (le digo que coma) y duda (dudo que vaya); 2) casos en los que la negación y la interrogación inducen el subjuntivo (belief-negative: no creo que vea y belief-interrogative: ¿cree que tenga dinero?). Si el verbo de la oración principal no va en presente sino en alguna forma de pasado, Bórquez indica que el modo subjuntivo emplea las formas del imperfecto (quería que fuera, sentí que fuera, me alegré de que hablara, era necesario que fuera, no creía que viera, dudé que fuera), tiempo que también se utiliza en las condicionales (si pudiera-pudiese cantar, lo haría con mucho gusto).

Una vez aclarados los contextos y principales usos y restricciones del subjuntivo, se ocupa de las formas de los distintos tiempos del modo y de sus respectivos paradigmas verbales regulares e irregulares.

Las últimas líneas están dedicadas al segundo imperfecto de subjuntivo o condicional, a sus usos, según Bórquez, de conjetura, probabilidad o epistémico (sería las diez, ¿qué diría?) y a su formación a partir "del futuro de indicativo" (1914, 52, cita traducida por la autora).

26 La primera aclaración se encuentra en la nota "el presente de subjuntivo se usa aquí [mañana cuando nos levantemos] para expresar no solo el tiempo, sino también una condición" $(1917,56)$ y la segunda en la nota "[antes de salir llegará el agente y dirá que le culpemos que no fue su culpa] el subjuntivo se usa después de un verbo que expresa mandato" (1917, 56, citas traducidas por la autora). 
La importancia que para Bórquez tenía la enseñanza del verbo se observa, además, en la segunda parte de la obra (el $39.5 \%$ del total), dedicada a una detallada exposición de la conjugación verbal y a una completa lista de los verbos con dos participios.

\subsection{La sintaxis}

Aunque en las notas a pie de página el verbo es la categoría protagonista, en algunas de ellas se ofrece también información sobre el resto de las categorías gramaticales, sus formas y funciones. Así, se muestran las formas del artículo (el, la, los, las, uno/un, una, unos, unas), de sus contracciones (al, del), las formas apocopadas de algunos adjetivos (buen/bueno, primer/ primero), de las conjunciones y sus variantes (y/e-and, o-or, para que-in order that), de los pronombres (me, nos, se, lo, la, él) o de algunos adverbios (en seguida-presently).

Así mismo, Aurelia Bórquez explica la concordancia dentro del grupo nominal, la presencia de $a$ delante de nombres de personas que funcionan como objeto directo o la naturaleza, posición y función de los pronombres tónicos y átonos. A este último tema le dedica varias notas en las que traza, a partir de las oraciones que van saliendo en las lecciones, el siguiente sistema pronominal español:

\begin{tabular}{lll}
\hline & Contexto & Explicación \\
\hline $\begin{array}{l}\text { Formas y } \\
\text { funciones }\end{array}$ & $\begin{array}{l}\text { Se lo pone [el sombrero] } \\
\text { Me lo desenredo [el pelo] }\end{array}$ & lo-acusativo masculino singular // objeto directo ${ }^{27}$ \\
& La pone en el papel [la pluma] & la-objeto directo femenino \\
& Uno al que no se le note el polvo [un sombrero] & $\begin{array}{l}\text { se-pronombre reflexivo } \\
\text { le-pronombre dativo }\end{array}$ \\
& Me clavo unas horquillas en él & él-término de una preposición \\
& ella-el sujeto de una oración o el término de preposición \\
\hline Posición & Se lo pone [el sombrero] & "el pronombre reflexivo precede a otros pronombres \\
& objeto" (1914, 23, cita traducida por la autora) \\
& Uno al que no se le note el polvo [un sombrero] & "el pronombre reflexivo precede al pronombre dativo" \\
& Cuando he cogido el botón, tiró de él hasta pasarlo por el ojal & $\begin{array}{l}\text { (1914, 64, cita traducida por la autora) } \\
\text { "los pronombres acusativo y dativo siguen al infinitivo, al } \\
\text { participio y al imperativo" (1914, 18, cita traducida por la } \\
\text { autora) }\end{array}$ \\
\hline
\end{tabular}

Tabla 5. Notas sobre contenidos gramaticales.

Las notas, finalmente, sirven para poner los equivalentes en inglés de algunas construcciones en que aparecen el resto de las categorías gramaticales y conocer así su caracterización, sus usos, sus significados, sus clases o sus restricciones. ${ }^{28}$ Entre ellas destacan las dedicadas, por su dificultad, a

27 La autora utiliza terminología tradicional sobre la que no introduce ninguna explicación ni caracterización. Sus alumnos, por su propia formación, debían de conocerla.

28 Algunos de estos ejemplos, similares y repetitivos, son: lo mismo-the same, después de darse los buenos días-after saying good morning, hasta las doce-until twelve, hasta las cinco-until five o'clock, después de la cena-after supper, después de lavarnos-after washing, a las siete-at seven, después de saludarnos-after greeting (saluting) us, entre más temprano mejor-the earlier the better, lo peor-the worst of it, cosa de las cuatro-about four, cerca de las ocho-about eight o'clock, antes de decidir-before deciding, antes de ser atendida-before being waited on, ¿quién es?-who is it?, cosa de las once-about eleven, son las ocho en punto-exactly eight o'clock, antes de volver-before returning, buen andar-good speed, antes de abrir-before opening, después de registrar-after inspecting. 
las locuciones (a pie-on foot, así como-as well as, por fin-finally, at last, al fin-finally, a bordo-on board, por supuesto-of course, a la vista-before you, para que-in order that, de vez en cuando-once in a while, otra vez-again, tal vez-perhaps) y a los cuantificadores (unos están de acuerdo-some of them agree, alguien llama-someone is at the door, un poco de papel-some paper). ${ }^{29}$

Pero, una vez más, las notas son insuficientes para exponer la gramática del español, ${ }^{30}$ por lo que Aurelia Bórquez dedica dos de las sesenta y una lecciones a presentar el paradigma y algunos ejemplos de los pronombres personales y los elementos constitutivos de las comparativas.

\subsection{El léxico}

El otro pilar sobre el que se asienta el método de Aurelia Bórquez es el léxico, y para su traducción y explicación se sirve de las notas a pie de página, de las lecciones, de dibujos y de repertorios léxicos temáticos y alfabéticos.

En las primeras incluye traducciones de diversas unidades léxicas, así como información, a través de varios contextos, de su formación en español y combinatoria (hora de la cena-supper time, conocido-acquaintance, ida y vuelta-return, cuarto de baño-bathroom, camisa de dormir-night-gown, ropa interior-underwear, pan tostado-toast, sello de correo-postage stamp, asado-broiled, leche nevada-ice cream, paseo de campo-picnic, tratar-to deal, pasado mañana-day after tomorrow, sala de espera-waiting room, la salida-the departure // salida-exit, coche de fumadores-smoking car, colcha blanca-white spread, sin ganas-unwillingly, da cuerda-winds, llevar chascoto be disappointed, eso va en gustos-that is according to one's taste, da la voz-calls, dimos las gracias-we expressed our appreciation, pierden de vista-lose sight of, estar de acuerdo-to agree). ${ }^{31}$

\footnotetext{
29 En las últimas lecciones de A series of Spanish conversations (1914), Aurelia Bórquez introduce entre paréntesis la traducción literal de algunas de las construcciones españolas, lo que debería resultar muy útil a sus estudiantes para entender la sintaxis del español y sus diferencias con la inglesa; ella lo justifica así, a propósito de "tocaron los lugares altos", "tal vez esta no es una expresión española pero estoy segura de que los estudiantes comprenderán muy bien” (1917, 60).

Algunos de estos ejemplos son: acabamos de llegar-we had just arrived (literal: we finished of to arrive), que vayan bien con-that may match (literal translation: that may go well with), aquí tiene usted-here is it (literal translation: here you have), había hecho facturar su equipaje-had had her baggage checked (literal: had make to check her baggage), uno al que no se le note el polvo-one which the dust does not show the dust (literal translation: one to the which the dust does not show itself to it), vestido de viaje-traveling dress (literal translation: dress of travel), a la vista-before you (literal translation: at the sight), hacerme la sorda-to pretend not to hear (literal: to make myself the deaf) o cerrado con llave-locked (literal: closed with key).

30 Las notas de su Elementary Spanish reader-Cuentos fáciles ilustrados (1917) son las mismas o muy similares: en frente-in front, se calientan-are heated, se hace-is made, es decir-that is to say, por la noche-in the evening, más fuerte-heavier, por la tarde-in the afternoon, ni yo-nor l, ¿quién pone la mesa?-Who sets the table?, ¿qué hora es?-What time is it?, más grande-larger, porque-because, otro día-next day, como de costumbre-as usual, tengo sueño-l'm sleepy, lo siento mucho-I am very sorry, a las ocho-at eight o'clock, de vez en cuandoonce in a while, la lengua de los gatos-the language of the cats, ten mucho cuidado-be very careful, pasaba muy mala vida-was ill-treated, cuando hayas muerto, haré que luzca un cirio-When you are dead, I shall burn a candle, llorando a gritos-crying aloud.

31 Las notas léxicas del Elementary Spanish reader-Cuentos fáciles ilustrados (1917) son, de nuevo, las mismas o muy similares: cuarto de dormir-bed-room, el comedor-the dining-room, gallinita-little hen, atrasado-slow, parado-stopped, año bisiesto-leap year, caña de pescar-fishing rod, caramba-goodness, domingo de PascuaEaster Sunday, dar un paseo-take a walk, botes de hojalata-tin cans, de rodillas-on her knees, puesta de solsunset, hora de la comida-dinner time.
} 
Las lecciones también son buena fuente de conocimiento del léxico del español: por un lado, porque cada una de las lecciones está dedicada a un núcleo temático o noción, en donde aparecen unidades léxicas de diverso tipo, su combinatoria o construcción y sus usos contextualizados, y, por otro, porque en varias ocasiones sirven específicamente para incluir listas de palabras. En la lección novena, dedicada al aseo personal, inserta el léxico de las partes de la cara ("me froto la cara, es decir, la frente, las sienes, los ojos, las cejas, los párpados, las pestañas, la nariz, las mejillas, los labios [...]", 1914, 15); la lección catorce, dedicada a la ropa, contiene una lista en la que se enumera desde la ropa interior al sobretodo pasando por la falda, la blusa, los pantalones, el cinto o el chaleco; y la segunda oración de la lección cincuenta y cinco, dedicada a los viajes, tiene la siguiente estructura: "solo dejaré para la maleta los artículos de tocador, es decir: cepillos para el cabello, los dientes, la ropa y las uñas, un espejo, polvo para la cara y las uñas, pasta para los dientes, etc." $(1914,65)$.

En el Elementary Spanish reader-Cuentos fáciles ilustrados (1917), Aurelia Bórquez emplea, para ayudar y estimular a sus estudiantes, imágenes, un recurso didáctico que debía servir para apoyar sus explicaciones, entretener a sus estudiantes y aclarar dudas en los casos más difíciles, pues las hay de muy diferente tipo y dificultad y acompañan a fábulas, cuentos y narraciones diversas:
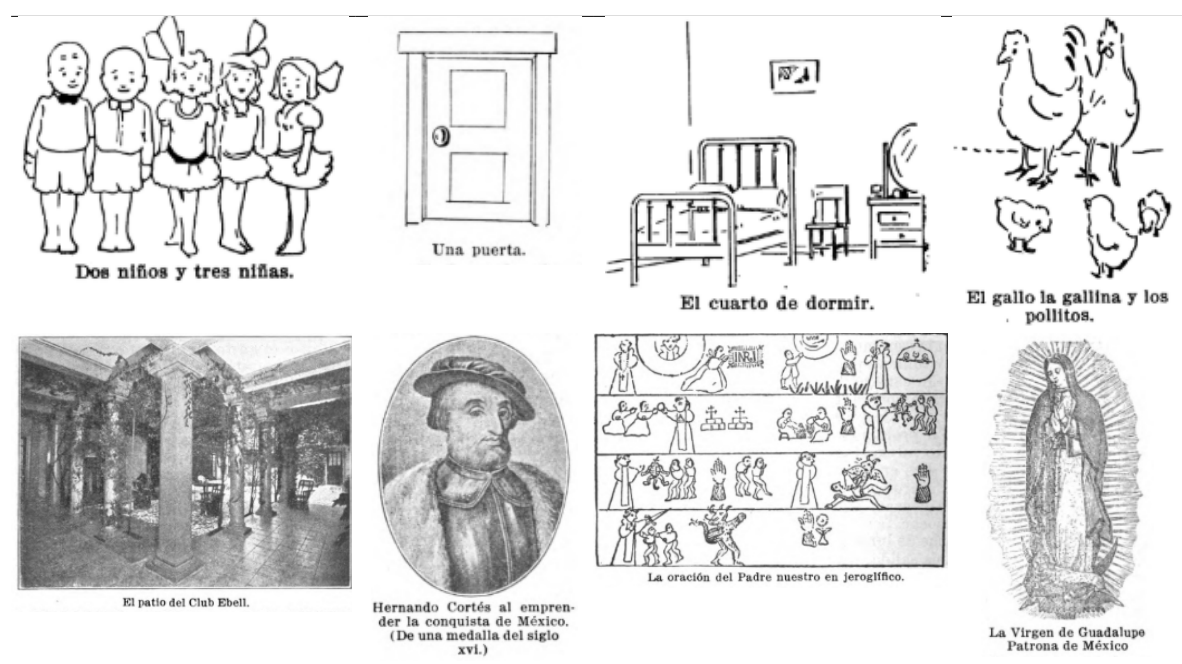

Tabla 6. Ilustraciones de los Cuentos fáciles ilustrados.

Tras las lecciones de A series of Spanish conversations, Bórquez recopila en apenas siete páginas (de la 81 a la 87) una nomenclatura, es decir, un repertorio temático ordenado a partir de diversos ámbitos designativos o materias que no ofrece definiciones de las unidades léxicas compendiadas, que recoge solo el léxico básico del español y que contaba, a comienzos del siglo XX, con una amplísima tradición. Las nomenclaturas nacieron para la enseñanza del griego, primero, y del latín, después, en la Antigüedad clásica, y, a partir del XVI, se utilizaron para aprender el léxico de las lenguas modernas: la apertura a Europa, el desconocimiento cada vez mayor del latín y la imposibilidad de utilizarlo como lingua franca, el crecimiento de las 
nuevas tierras extrapeninsulares y el aumento del comercio o la presencia de tropas para mantener la paz en los territorios conquistados obligaban a conocer las lenguas de las naciones vecinas y la organización conceptual del vocabulario resultó ser la mejor forma de lograrlo.

De ser un instrumento de acercamiento a una lengua muerta, pasó a reflejar las necesidades sociales, económicas y políticas de una sociedad que había cambiado. Estas ordenaciones siguieron adaptándose y publicándose en las centurias siguientes tanto en Europa como en América o Filipinas: en las nuevas tierras, primero se acomodaron a las necesidades de los misioneros y surgieron algunas con lenguas amerindias, y después, y debido a los profundos cambios que se produjeron y a las grandes oportunidades que ofrece América, se utilizaron también para la enseñanza de otras lenguas modernas (cfr. Alvar Ezquerra 2013, García Aranda 2006).

Bórquez recopila el léxico de los números cardinales, de la división del tiempo, los días de la semana, los meses del año, las estaciones, naciones, las divisiones de la tierra, las divisiones políticas, los títulos, las monedas, los parientes, las personas, las partes de la cara, las partes del cuerpo, las enfermedades, las lenguas, las profesiones, los instrumentos, las ocupaciones, los estudios, los artículos de costura, los colores, las medidas, las flores, las diversiones, las frutas, los árboles, las bebidas, las legumbres, las aves, los animales, los granos, los vehículos, los implementos (instrumentos) y los metales.

Aunque la mayoría de estos epígrafes son frecuentes en las nomenclaturas de todos los tiempos, ${ }^{32}$ este repertorio muestra, como es habitual, la adaptación a la realidad americana de comienzos de siglo: ${ }^{33}$ entre las monedas y las medidas se citan el centavo, el penique, la pulgada (también cuadrada y cúbica), el pie (también cuadrado y cúbico), la yarda (también cuadrada y cúbica), la milla, el galón o la onza, entre las profesiones se encuentran el mecánico, el operario de teléfono o el motorista, entre los estudios aparecen la economía política y la cultura física, entre las diversiones se enumeran el hockey, el basket-ball o el cinematógrafo, entre los vehículos se mencionan el automóvil, la motorcicleta o el tranvía y entre los instrumentos se recogen la máquina de segar o la trilladora.

Finalmente, Aurelia Bórquez incorpora al final de sus tres obras, A series of Spanish conversations (1914, 114-132), Leyendas históricas mexicanas costumbes [sic] y mitología (1915, 169-203) y Elementary Spanish reader-Cuentos fáciles ilustrados (Los Ángeles, 1917, 122-157), vocabularios

32 Las nomenclaturas no permanecieron estáticas y ajenas a los cambios que se produjeron a lo largo del tiempo en la sociedad: a) de presentar una ordenación teocentrista en las primeras centurias pasan a una antropocentrista; b) el contenido léxico varió con el paso del tiempo, de manera que se redujeron unos epígrafes (por ejemplo, sobre el mar o las enfermedades) y se introdujeron o ampliaron otros (listas de topónimos, de antropónimos o el vocabulario de la escuela, del estudio); c) desde finales del siglo XVIII empiezan a incluir también vocabularios independientes con adjetivos, verbos, artículos, pronombres, preposiciones, adverbios, conjunciones e interjecciones, ordenados unas veces semánticamente, otras a partir de criterios gramaticales y otras alfabéticamente, lo que "no parece el mejor método para recordar el vocabulario que se va a prendiendo" (Alvar Ezquerra 2013, 390).

33 La influencia americana no solo se observa en la realidad extralingüística sino también, como se verá, en la forma lingüística de las unidades léxicas recogidas (extranjerismos crudos y adaptados). 
alfabéticos con las voces aparecidas en las obras. Los tres repertorios son español-inglés y están formados por sencillos artículos lexicográficos que ofrecen la traducción en la segunda lengua de sustantivos, adjetivos, verbos, preposiciones, adverbios (también los terminado en -mente), participios, conjunciones y pronombres lematizados unas veces en su forma canónica y otras, no (hay formas plurales como arneses, amigos, criollos, cuartillos, deformes, estas, fieles, frutales, máquinas, ociosas, preceptos, rosas o truenos y verbos conjugados como abdicó, acepto, acuestan, déjame, dejara, estamos, fueran, llevando, mandó, matarnos, merecerían, obsérvalo, ocultándose, prepararán, sabemos, vuelvan). Junto a ellos se cuelan, en contadas ocasiones, algunos topónimos y antropónimos españoles y mexicanos (España, Estremadura, Coyoacán, Mitla, Tenochas, Tenochtitlan).

Los artículos lexicográficos suelen ser sinonímicos simples, si bien, en ocasiones, las diferencias entre las dos lenguas y la existencia en ellas de palabras polisémicas y homónimas obligan a incluir más de una traducción de la forma española:

\begin{tabular}{ll}
\hline Sinonímicos simples & Sinonímicos complejos o acumulativos \\
\hline acabar, to finish & abrojo, thistle, thorn, prickle \\
aceite, oil & acudir, to go to, to hasten, to assist \\
acercar, to approach & acusar, to accuse, to acknowledge \\
adornos, trimming & cocinera, cook-maid, kitchen-maid \\
apetecer, to have appetite & la, the her, it \\
labio, lip & lanas, wools, wool cloth \\
lamentar, to lament & le, him, her, it, to him, to her, to it \\
lástima, to hurt & participar, to inform, to share \\
lavar, to wash & paseo, outing, drive \\
lechero, milkman & pegar, to stick, to whip \\
leer, to read & raya, line, part, stripe \\
librería, book store & real, real, royal \\
pecado, sin & recomendación, recommendation, praise \\
pedido, order & tirando, throwing, pulling \\
peinar, to comb & toca, touches, plays \\
pensamiento, thought & todo, all, everything \\
ramillete, bouquet & reforma, reform, selves \\
razón, reason & regidor, alderman, perfect \\
realistas, king's troops & reloj, watch, clock \\
recibirlo, to receive him, it & tú, you, your \\
recitar, to recite & tuya, your, yours \\
todavía, yet & viaje, trip, journey \\
viajar, to travel & vuelta, turn, return \\
vuelve, return & yerba, grass, herb \\
y, and &
\end{tabular}

Tabla 7. Ejemplos de artículos lexicográficos.

Son, en suma, diversos recursos tradicionales ideados con el fin de recopilar el léxico español y presentarlo de manera fácil a los alumnos del Ebell.

\subsubsection{El español de América}

El origen mexicano de Aurelia Bórquez explica que en sus obras aparezcan rasgos propios del español de América, especialmente en el vocabulario. En las Leyendas históricas mexicanas costumbes [sic] y mitología incluye un "Vocabulary of indian words" con topónimos, antropónimos y americanismos 
crudos que trata de traducir o explicar en inglés, ${ }^{34}$ pues su aparición es frecuente en las leyendas y narraciones que recoge en la obra:

\begin{tabular}{|c|c|c|}
\hline Topónimos & Antropónimos & Nombres comunes \\
\hline $\begin{array}{l}\text { Astlán, a city } \\
\text { Cuahutitlán, a city } \\
\text { Chapultepec, the summer residence of the } \\
\text { Mexican president } \\
\text { Malinche, the name the Indians gave Hernán } \\
\text { Cortez }\end{array}$ & $\begin{array}{l}\text { Ahmizotl, a very bad king } \\
\text { Huitzlihuitl (humming bird feather) an aztec } \\
\text { king } \\
\text { Moctezuma, the last Aztec king } \\
\text { Xochipapalotl, a chichimeca prince }\end{array}$ & $\begin{array}{l}\text { Capuchin, a nahua dress } \\
\text { Mije, black tiger } \\
\text { Ocelotl, tiger or a knight of an order } \\
\text { Tenchtl, cactus plant } \\
\text { Teponaxtles, musical instrument }\end{array}$ \\
\hline
\end{tabular}

Tabla 8. Ejemplos de su "Vocabulary of indian words".

En las otras dos obras también se cuelan algunas voces propias del español de México, ${ }^{35}$ lo que las convierte en valiosos testimonios del español usado en zonas americanas: bebidas y comidas como atole, balché, camote, enchilada, frijol, jigote, leche nevada, papa, picle, pinole, posol, pulque, quelite o tortilla, vestidos y tejidos como ayate, huipil o tilma, plantas como ahuehuetes, camote, ceiba, chachaca, chile, ejote, elote, maguey, mamey, milpa o tuna (tunal), animales como el ocelote o el chanate, objetos varios como macana, fosforera, pichel, frazada, pizarrón, tambora, hamaca o trastos de mesa, acciones como alistar, empacar, ordenar (por pedir un alimento o comida), mandar (por hacer cumplir), platicar, tomar (por coger), embijar ('ensuciar, 'manchar'), cobrar miedo (con valor incoativo + sustantivo negativo) o voltear, comercios como la dulcería o la florería, lugares como el rancho u oficios como la recamarera. Así como otras unidades léxicas que se explican por influencia o calco del inglés como cuilta (de quilt, colcha), sala de clases (de classroom), jugar solitario/jugar algo (uso como transitivo procedente de to play tennis/football) o manicurar (de to manicure).

Los repertorios, además de para documentar americanismos léxicos, son útiles para ejemplificar algunos rasgos gramaticales también característicos del español americano, como la preferencia por algunos morfemas derivativos en las creaciones sufijadas (cepillero, calentadera), el uso de la sufijación diminutiva (muchisísimo, poquitititito), el uso de algunos adverbios (luego por rápidamente), casos de leísmos (les decía que verían un águila que les conduciría a su nido, si le reconocía como jefe, no le mires, allí le vemos en el grabado), la preferencia por las formas en -ra del imperfecto de subjuntivo (Bórquez pone la forma en -ra y, entre paréntesis, la forma en -se), el uso del verbo modal querer en imperfecto de subjuntivo en expresiones desiderativas (los muchachos quisieran jugar algo en que todos tomaran parte), valores y usos de las preposiciones (martes en la noche, he estado aprendiendo la lengua por ocho meses, caminaron por un largo rato),

34 Se cuela, no obstante, alguna forma que no es náhuatl como chalupa, nombre de embarcación que tomamos del francés.

35 No es el objetivo de este trabajo el léxico americano, por lo que no me detengo en clasificar y caracterizar los distintos tipos de americanismos léxicos (americanismos no determinados diacrónicamente y americanismos determinados diacrónicamente, $y$, dentro de estos, los que se producen por pérdida léxica y los que se explican por alteración semántica) que se encuentran en las obras de Aurelia Bórquez (cfr. Bohórquez 1984, Buesa Oliver y Enguita Utrilla 1992, Company 2010, Frago 1999, Moreno de Alba 1992 y 2007, Ramírez Luengo 2015 y 2017). 
interferencias entre el verbo ser y el verbo estar (si no estás listas, eres perdida) o algunas construcciones sintácticas (favor de decirme la hora). ${ }^{36}$

La obra de Bórquez resulta, por tanto, un buen ejemplo de la presencia y tratamiento de la variación en las clases de ELE, así como de la compleja realidad lingüística del sur de Estados Unidos a comienzos del siglo xx. La autora quiso adaptar su curso de español al contexto americano y al Club Ebell, lo que exigía reflejar un ambiente muy concreto en el que mexicanos de clase alta enseñaban su lengua a estudiantes también de elevada formación.

\subsection{Géneros discursivos y productos textuales}

Aurelia Bórquez rechaza, como hemos visto, la exposición teórica de la gramática del español y defiende, en cambio, aprenderla a través de oraciones y relatos. A las primeras, como se ha mostrado, les dedica la primera parte de su A series of Spanish conversations, mientras que los segundos son los protagonistas del resto de su obra.

Los textos permiten a nuestra autora afianzar la enseñanza de español en diferentes contextos o ámbitos (público, profesional) y formar a sus estudiantes en contenidos pragmáticos, culturales y sociales que, sumados a los lingüísticos, les facilitaría la competencia comunicativa. Para ello, elige fábulas clásicas (el perro y su sombra, el gallo y la joya, el oso y la mona, la liebre y la tortuga), textos comerciales (presentación de un amigo, para solicitar empleo), ${ }^{37}$ poesías (Bécquer, Gutiérrez Nájera), teatro en verso ( $\mathrm{La}$ muñeca del modernista mexicano Manuel Gutiérrez Nájera), producciones textuales de sus alumnos (María, El reloj), cuentos tradicionales (Caperucita roja), anécdotas (La señorita Ebell, de Los Ángeles, en México), leyendas mexicanas (el origen de los colores y del emblema de la bandera mexicana, El puente del clérigo, Leyenda de la Virgen de Guadalupe, El vencedor del sol, Usos y costumbres de la tribu maya), biografías de políticos ilustres (Miguel Hidalgo y Costilla, general José María Morelos, general Antonio López de Santa Ana, general Porfirio Díaz), textos morales aztecas (consejos de un padre a un hijo, consejos de una madre a una hija) o narraciones (el bautismo, el entierro).

Aunque la presencia de textos literarios, históricos y comerciales no es nueva en la historia de la enseñanza de español, Bórquez los adapta a la realidad americana, en donde el componente mexicano es mucho más próximo que el europeo. Su propuesta, original y diferente, cumple idénticas funciones que otros textos tradicionales como manifestaciones del español, lo que la convierte en una forma efectiva de aprender el contexto de uso de una lengua.

\footnotetext{
36 Para estos y otros rasgos gramaticales, léxicos y pragmáticos del español de América, véase Aleza Izquierdo y Enguita Utrilla 2010 y la bibliografía allí incluida.

37 Estos textos están localizados en México, Guadalajara, Chihuahua, Hermosillo, Cualiacán o Zaragoza y firmados por Pedro Esteve, Francisco Suárez, Juan Chávez, Juan Ocha o José Valdez.
} 
Las oraciones y los textos de Aurelia Bórquez, en suma, aspiran a volverse el medio para que sus alumnos se conviertan en usuarios plurilingües y pluriculturales del español, pues abordan diferentes ámbitos y situaciones, temas, objetivos comunicativos, textos y canales de comunicación y distintas actividades y estrategias, con el fin de desarrollar en ellos las competencias comunicativas que requiere el usuario de la lengua.

\subsection{Referentes culturales}

La lengua no puede desligarse de la sociedad y de la cultura que la habla, por eso Aurelia Bórquez introduce, en todo momento, aspectos relacionados con la vida en México o con la vida de los mexicanos de clase alta en el sur de Estados Unidos. Así, por ejemplo, los protagonistas de sus oraciones leen libros y periódicos y escriben con papel, tintero y pluma; se visten con faldas, blusas, cintos, pantalones, camisas, corbatas, chalecos, sombreros, guantes, camisas de dormir; se peinan con cepillos, peines y polvos que guardan en delicados tocadores; usan zapatos de cordones y zapatos de botones; desayunan café con leche, crema y azúcar, jamón, huevos fritos, pan tostado y fruta; comen sopa, pollo asado, pescado frito, ensalada, legumbres, vino, aceitunas, picles, leche nevada, pastel, frutas, té helado, nueces y pasas; trabajan en oficinas con elevadores hasta las cinco de la tarde; los hombres tienen importantes negocios; se levantan a las siete y media y se acuestan a las diez; tienen criadas que anuncian el almuerzo y la cena tocando una campanilla, recamareras que limpian y mantienen la casa, cocineras que preparan y sirven la comida y jardineros que cuidan el exterior; poseen casas con bibliotecas, escritorios, cajitas, teléfono, tocadores, baúles, cocinas de gas, platos, platillos, tazas, cuchillos, tenedores, cucharas, saleros, pimenteros, chimeneas, relojes; entre sus pasatiempos están el violín, dar paseos, hacer solitarios, hacer fotografías con cámaras Kodak, bailar, visitar a amigos o ir a las carreras de automóviles; curan a los niños con pomada, linimento y peróxido; visitan a la modista y ven figurines de París; compran en la botica polvos para la manicura y preparaciones para quitar la caspa y dar brillo al cabello; rezan antes de irse a dormir; viajan por Europa y a Ciudad de México, llamada "el París de las Américas" (1914, 72). En los escritos de 1915 y 1917, como se ha dicho, están presentes algunos episodios y algunos personajes históricos mexicanos.

La inclusión de referentes culturales permite, por tanto, ampliar y mejorar el conocimiento de los alumnos, dado que la lengua aparece utilizada en su entorno social y en situaciones reales (diálogos entre marido y mujer, entre padres e hijos, entre compañeros, entre amigos, entre hermanos) que resultan imprescindibles para que el acto de comunicación sea eficaz y exitoso.

\section{Conclusiones}

La obra de Aurelia Bórquez muestra la labor de una profesora que, inspirada por el Club Ebell y por el contexto social que vivió, decidió componer un método de aprendizaje de español adaptado a la realidad del sur de Estados Unidos. En sus páginas reúne oraciones, textos de diferente tipología, algún 
compendio gramatical y varios repertorios léxicos con el fin de enseñar de manera natural y directa a sus estudiantes.

Su conocimiento del español y del inglés, su formación como maestra, su pertenencia al Club Ebell, el origen mexicano y español de sus padres y abuelos y sus continuos contactos y viajes a México motivaron su propuesta didáctica, que, aunque poco original, trata de adaptar a la experiencia y a las circunstancias de sus alumnas, mucho más familiarizadas, por la cercanía y por la historia, con México que con España. Logra así un método que refleja la variación lingüística condicionada por la geografía y por los factores socioculturales presentes en la ciudad de Los Ángeles a comienzos del siglo XX.

La obra de Bórquez es, a falta de un estudio pormenorizado de la lengua que recoge, una valiosa muestra de los rasgos lingüísticos de los hablantes de herencia en un momento crucial en la historia del español, pues en ella aparecen algunas características de la pronunciación, la morfología, la sintaxis y el léxico que, con el paso de los años, identificarán al español del sur estadounidense.

Por otro lado, y pese a que su método de enseñanza de español otorgaba un papel preponderante al profesor, pues debía dominar el español y ser el guía de la clase en todo momento, aunque la ausencia de gramática explícita acarreaba algunas limitaciones y a pesar de que en ocasiones ha de recurrir a los métodos tradicionales en forma de listas de verbos, pronombres o unidades léxicas, el método Bórquez constituye un interesante y sorprendente capítulo de la historia de la enseñanza del español en Estados Unidos. 


\section{Q Bibliografía}

" Acevedo, Rebeca. 2006. "El español californiano durante la segunda mitad del siglo XIX”. Actas del XV Congreso Internacional de ALFAL, agosto de 2006, Montevideo, CDRom.

》Aleza Izquierdo, Milagros y José M.a Enguita Utrilla. 2010. La lengua española en América: normas y usos actuales. Valencia: Universitat de València.

»Alonso, Amado. 1967. De la pronunciación medieval a la moderna en español. Madrid: Gredos [2 vols.].

» Alvar, Manuel. 1996. “Los Estados Unidos”. En Manual de dialectología hispánica. El español de América, dirigido por Manuel Alvar, 90-100. Barcelona: Ariel.

» Alvar Ezquerra, Manuel. 2013. Las nomenclaturas del español. Siglos XV-XIX. Madrid: Liceus.

» Bancroft, Hubert H. 1886a. History of New Mexico and Arizona. San Francisco: The Bancroft Press.

" Bancroft, Hubert H. 1886b. California Pastoral. San Francisco: The Bancroft Press.

" Blanco, Antonio S. 1971. La lengua española en la historia de California. Madrid: Cultura Hispánica.

"Bohórquez, Jesús G. 1984. Concepto de americanismo en la historia del español. Bogotá: Instituto Caro y Cuervo.

» Bórquez, Aurelia. 1914. A series of Spanish conversations in the conjugational order. A series of commercial letters and short stories. Los Ángeles: Aurelia Bórquez.

» Bórquez, Aurelia. 1915. Leyendas históricas mexicanas costumbes [sic] y mitología. Los Ángeles: Aurelia Bórquez.

»Bórquez, Aurelia. 1917. Elementary Spanish reader-Cuentos fáciles ilustrados. Los Ángeles: Aurelia Bórquez.

» Buesa Oliver, Tomás y José M.a Enguita Utrilla. 1992. Léxico del español de América: su elemento patrimonial e indígena. Madrid: Mapfre.

"Company, Concepción. 2010. "Introducción”, en Academia Mexicana de la Lengua, Diccionario de Mexicanismos (XV-XXIII). México DF: Siglo XXI.

》 Fontanella de Weinberg, M. Beatriz. 1992. El español de América. Madrid: Mapfre.

"Frago, Juan Antonio. 1999. Historia del español de América. Madrid: Gredos.

" García Aranda, M.- Ángeles. 2006. La enseñanza del léxico latino en el Renacimiento: Nebrija, su "Lexicon seu parvum vocabularium" y las nomenclaturas del español. Jaén: Servicio de Publicaciones.

" García Aranda, M.․ Ángeles. 2020. “Ortografía y pronunciación en la serie textual americana del método Ollendorff". Bulletin of Hispanic Studies / Bulletin of Contemporary Hispanic Studies., 97-9: 899-930.

"Germain, Claude. 1993. Évolution de l'enseignement des langues: 5000 ans d'histoire. París: Nathan/CLE international.

" Germain, Claude. 1995. "Fondements linguistiques et psychologiques de la méthode 
des séries de François Gouin (1880)". Histoire Épistémologie Langage, 17-1: 115-141.

" Gouin, François. 188o. L'Art d'enseigner et d'étudier les langues. París: Fischbacher.

» Howatt, Anthony P. R. 1984. A History of English Language Teaching. Oxford: Oxford University Press.

» Lamar Prieto, Covadonga. 2018. Los californios: historia sociolingüística de California en el siglo XIX. Madrid: Iberoamericana/Vervuert.

» Lipski, John M. 1996. El español de América. Madrid: Cátedra.

》Marcos Marín, Francisco. 2007. “Tres líneas léxicas del español de los Estados Unidos de América”. En Léxico español actual, editado por Luis Luque Toro, 127-142. Venecia: Universita Ca'Foscari.

" Martínez Alcalde, M. ․ José. 2010. La fijación ortográfica del español: norma y argumento historiográfico. Bern: Peter Lang.

» Moreno de Alba, José G. 1992. Diferencias léxicas entre España y América. Madrid: Mapfre.

》 Moreno de Alba, José G. 1993. El español en América. México: Fondo de Cultura Económica, 2. ${ }^{\text {a }}$ ed.

»Moreno de Alba, José G. 2007. Introducción al español americano. Madrid: Arco/Libros.

" Moreno de Alba, José G. y Giorgio Perissinotto. 1988. "Algunas consideraciones sobre el español de Santa Bárbara”. Nueva Revista de Filología Hispánica, XXXVI (1): 171-201.

" Moreno Fernández, Francisco. 2008. “Caracterización del español patrimonial”. En Enciclopedia del español en los Estados Unidos. Anuario del Instituto Cervantes 2008, coordinado por Humberto López Morales. Madrid: Instituto Cervantes. Disponible en: https:// cvc.cervantes.es/lengua/anuario/anuario_o8/default.htm

" Moyna, María Irene. 2010. "Varieties of Spanish in Post-Annexation California (18481900). En Spanish of the Southwest: A Language in Transition, editado por Daniel Villa y Susana Rivera-Mills, 27-44. Madrid/Frankfurt: Iberoamericana/Vervuert.

" Moyna, M. Irene, Wendy Decker y M. Eugenia Martín. 2005. "Spanish/English Contact in Historical Perspective: 19th Century Documents of the Californias". En Selected Proceedings of the 7th Hispanic Linguistics Symposium, editado por David Eddington, 169-179. Somerville, MA: Cascadilla Proceedings Project.

"Parodi, Claudia. 2009. "Normatividad y diglosia en Los Ángeles: un modelo de contacto lingüístico". En Normatividad y uso lingüístico, editado por Fulvia Colombo Airoldi y Mํㅡㄹ de los Ángeles Soler Arechalde, 47-67. México: Universidad Nacional Autónoma de México.

"Parodi, Claudia. 2011. "El otro México: español chicano, koineización y diglosia en Los Ángeles, California", en Realismo en el análisis de corpus orales, editado por Pedro Martín Butragueño, 217-243. México: El Colegio de México.

"Perissinotto, Giorgio. 1992. "El español de los presidios y prisiones de California en 1782". Aplicada, 10.15-16: 35-47.

»Perissinotto, Giorgio. 1998. Documenting Everyday Life in Early Spanish California. Santa Barbara: Santa Barbara Trust for Historical Preservation.

»Quesada Pacheco, Miguel Ángel. 200o. El español de América. Cartago: Editorial Tecnológica de Costa Rica.

»Quilis, Antonio y Mª José Quilis Sanz. 2002. El español en América, Madrid: UNED.

"Ramírez Luengo, José Luis. 2015. “El americanismo y la historia: Algunas pautas diacró- 
nicas de creación de americanismos (léxicos)". Miradas. Revista de Investigación de la Universidad Tecnológica de Pereira, 13: 114-123.

»Ramírez Luengo, José Luis. 2017. "Aspectos metodológicos en el estudio histórico del léxico americano: conceptos, ejemplificación y tareas para el futuro". Moenia. Revista lucense de lingüistica \& literatura, 23, Ejemplar dedicado a: Morfosintaxis y semántica del verbo en español: historia y descripción: 603-619.

»Real Academia Española. 1914. Diccionario de la lengua castellana. Madrid: Imprenta de los sucesores de Hernando.

»Real Academia Española y Asociación de Academias de la Lengua Española. 2010. Ortografía de la lengua española. Madrid: Espasa.

" Richards, Jack C. y Theodore S. Rodgers. 1986. Approaches and Methods in Language Teaching. Cambridge: Cambridge University Press.

"Richards, Jack C. y Theodore S. Rodgers. 1998. Enfoques y métodos en la enseñanza de idiomas. Madrid: Cambridge University Press.

"Sánchez Pérez, Aquilino. 1992. Historia de la enseñanza del español como lengua extranjera. Madrid: SGEL.

"Terreros, Esteban de. 1767-1788. Diccionario castellano con las voces de ciencias y artes y sus correspondientes en las tres lenguas francesa, latina e italiana. Madrid: Viuda de Ibarra, 3 vols.

»The Ebell of Los Angeles. 1923. [Monthly bulletin. Oct. 1921-jun. 1923]. Los Ángeles: Ebell of Los Ángeles.

» The Ebell of Los Angeles. 1927. [Monthly bulletin. Oct. 1923-jun. 1927]. Los Ángeles: Ebell of Los Ángeles.

"Titone, Renzo. 1968. Teaching Foreign Languages. An Historical Sketch. Washington, D.C.: Georgetown University Press.

»Vilar, Mar. 200o. El español, segunda lengua en los Estados Unidos. De su enseñanza como idioma extranjero en Norteamérica al bilingüismo. Murcia: Universidad de Murcia. 